\title{
Causality and preventability assessment of adverse drug events of antibiotics among inpatients having different lengths of hospital stay: a multicenter, cross-sectional study in Lahore, Pakistan
}

\author{
Anum Saqib ${ }^{1+}$, Muhammad Rehan Sarwar ${ }^{1,2^{*+}}$ (D), Muhammad Sarfraz $z^{3}$ and Sadia Iftikhar ${ }^{2}$
}

\begin{abstract}
Background: A large number of hospital admissions are attributed to adverse drug reactions (ADRs) and they are the fifth leading cause of death worldwide. The present study aimed to assess the causality and preventability of adverse drug events (ADEs) of antibiotics among inpatients having different lengths of hospital stay.

Methods: A prospective, observational study was conducted in four tertiary-care public sector hospitals of Lahore, Pakistan. Study population consisted of hospitalized patients who were prescribed one or more antibiotics. Data were collected between 1st January, 2017 and 30th June, 2017 from 1249 patients. Naranjo score, modified Schumock and Thornton scale were used for causality and preventability assessments, respectively. Medication errors (MEs) were assessed by MEs tracking form. SPSS and Microsoft Excel were used for data analysis.

Results: A total of 2686 antibiotics were prescribed to 1249 patients and 486 ADEs were found. The preventability assessment revealed that most of the ADEs (78.8\%) were found among patients having long length of stay (LOS) in hospital and were preventable (59.3\% of the ADEs were definitely preventable while $44.7 \%$ were probably preventable) and caused by MEs including wrong drug (40.1\%) and monitoring errors (25\%). The errors were caused due to non-adherence of policies (38.4\%) and lack of information about antibiotics (32\%). Most of the non-preventable ADEs or ADRs among patients having long and short LOS in hospital were "probable" (35.5\%) and "possible" (35.8\%), respectively. Logistic regression analysis revealed that $A D E s$ were significantly less among females $(O R=0.047,95 \% \mathrm{Cl}$ $=0.018-0.121$, $p$-value $=<0.001)$, patients aged $18-52$ years $(\mathrm{OR}=0.041,95 \% \mathrm{Cl}=0.013-0.130, p$-value $=<0.001)$, patients with ARTIs (OR $=0.004,95 \% \mathrm{Cl}=0.01-0.019, p$-value $=<0.001)$, patients prescribed with 2 antibiotics per prescription $(\mathrm{OR}=0.455,95 \% \mathrm{Cl}=0.319-0.650, p$-value $=<0.001)$ and patients with long $\operatorname{LOS}(\mathrm{OR}=14.825,95 \%$ $\mathrm{Cl}=11.198-19.627, \mathrm{p}$-value $=<0.001)$.

Conclusion: Antibiotics associated definitely preventable ADEs were more commonly found in patients having long LOS in the inpatient departments because of MEs and lack of proper pharmacovigilance system. The ADRs showed a probable and possible causal association with both $\beta$-lactams and non $\beta$-lactams antibiotics.
\end{abstract}

Keywords: Antibiotics, Adverse drug reactions, Adverse drug events, Length of stay, Causality, Preventability

\footnotetext{
* Correspondence: rehansarwaralvi@gmail.com

${ }^{\dagger}$ Anum Saqib and Muhammad Rehan Sarwar contributed equally to this

work.

'Department of Pharmacy, The Islamia University of Bahawalpur, Bahawalpur,

Punjab, Pakistan

${ }^{2}$ Akhtar Saeed College of Pharmaceutical Sciences, Lahore, Pakistan

Full list of author information is available at the end of the article
}

(c) The Author(s). 2018 Open Access This article is distributed under the terms of the Creative Commons Attribution 4.0 International License (http://creativecommons.org/licenses/by/4.0/), which permits unrestricted use, distribution, and reproduction in any medium, provided you give appropriate credit to the original author(s) and the source, provide a link to the Creative Commons license, and indicate if changes were made. The Creative Commons Public Domain Dedication waiver (http://creativecommons.org/publicdomain/zero/1.0/) applies to the data made available in this article, unless otherwise stated. 


\section{Background}

According to the World Health Organization (WHO) adverse drug reactions (ADRs) are defined as, "any response to a drug which is noxious, unintended, and that occurs at doses normally used in man for the prophylaxis, diagnosis, or therapy of disease" [1]. On the basis of the National Coordinating Council for Medication Error Reporting and Prevention (NCC MERP) recommendations, adverse drug events (ADEs) can be termed as injuries which are either related to the medical interventions or the dose of the drugs [2]. As ADEs are not always associated with the use of drugs, so all ADRs can be attributed as ADEs but all ADEs can never be the result of ADRs. The risk of ADRs is associated with almost all the prescribed therapeutic agents. But these untoward effects may vary in terms of severity level i.e., from minor to severe or lethal [3].

The duration of a single episode of hospitalization i.e., length of stay (LOS) can be considered as one of the risk factors of ADEs. The stay of patient for each additional day in hospital increases the probability of developing ADEs because this provides more time for an ADE to occur [4]. According to a study if the LOS in hospital is prolonged then there will be an increment of $6 \%$ in the development of ADEs with the stay for each additional day [5]. Similarly, a Swedish study demonstrated ADRs as one of the most recurrent causes of mortality because one out of every seventh inpatient suffers from ADR during hospital stay [6]. A study demonstrated the prevalence rate of ADEs among hospitalized patients of England as 3.2\%, Germany as $4.8 \%$ and the United States of America (USA) as 5.6\% [7]. Furthermore, it is estimated that the incidence of life threatening ADRs during hospital stay ranges from 0.05 to $0.09 \%$ $[8,9]$. Besides LOS, a meta-analysis revealed age, gender and drug exposure as the major contributing factors towards ADRs [8].

The prime role of pharmacovigilance system is to ensure patient safety due to its involvement in comprehension, recognition and prevention of ADEs [10]. The identification of ADEs still remains a major challenge for physicians. The causal association of ADRs with the drug is mandatory to evaluate in pharmacovigilance because it gives an insight about risk to benefit ratio of a particular drug on individual level [11]. Thus, poor monitoring and reporting system of ADEs has dramatically increase the patient's LOS in hospital and economically burdened the healthcare system [12].

Antibiotics are among the most frequently prescribed therapeutic agents among hospitalized patients of all age groups [13]. It is estimated that more than half of the hospitalized patients are prescribed with antibiotics $[14,15]$. It has been reported that the excessive use of antibiotics is associated with problems like antibiotic resistance [16]. Moreover, the higher rate of prescribing these agents has increased the chances of MEs up to several folds which in turn leads to the development of preventable ADEs [17]. In correspondence to this fact, a study conducted in Netherland report the incidence of preventable ADEs among $0.2 \%$ of the hospitalized patients [18]. A study conducted by Shehab, et al. documented that 19\% patients visited emergency department due to antibiotics-associated ADRs [19]. Multiple reasons make inpatients more prone to ADRs which may include; 1 ) the trend of administering multiple antibiotics among inpatients. and 2) mostly, the inpatients comprises of pediatrics, geriatrics or patients having various co-morbidities and all these patients have high risk of developing ADRs [20, 21]. There is a dearth of proper pharmacovigilance surveillance system in Pakistan on regional, provincial and national level which leads to poor availability of data regarding antibiotic associated ADEs and its association with the LOS. Previously published studies do not give insight on this issue. The present study aims to assess the causality and preventability of adverse drug events of antibiotics ( $\beta$-lactams and non $\beta$-lactams) among inpatients having different lengths of hospital stay.

\section{Methods}

\section{Study design and settings}

A prospective, cross-sectional, observational study was conducted in four public tertiary care hospitals (Mayo hospital, Jinnah hospital, General hospital, and Services hospital) of Lahore, Punjab province of Pakistan. According to latest Pakistani census, the total population living in Pakistan is 201,995,540 [22]. Lahore is the most populous city of Punjab province of Pakistan, with a total population of $11,126,285$ [23]. The study settings lack pharmacovigilance centers and ADEs registers. The characteristics of the selected hospitals are summarized in Table 1.

\section{Study inclusion criteria}

The study population included the patients of all age groups, admitted in general internal medicine ward and pediatric ward, prescribed with antibiotics on the basis of differential diagnosis for $\geq 24 \mathrm{~h}$.

\section{Study exclusion criteria}

All the patients with medical history of cardiac diseases, hepatic and renal insufficiencies, ear, nose and throat (ENT) disorders and unavailability of information regarding LOS in the hospital were excluded from this study. 
Table 1 Characteristics of selected hospitals

\begin{tabular}{llllll}
\hline Sr. no. & Characteristics & Mayo hospital & Jinnah hospital & General hospital & Services hospital \\
\hline 1 & Number of beds & 2400 & 1500 & 1300 & 1196 \\
2 & Inpatients visit last year & 343,114 & 217,245 & 134,491 & 125,868 \\
3 & Prescribers/Medical officers & 550 & 348 & 300 & 274 \\
4 & Nurses & 500 & 313 & 271 & 249 \\
5 & Pharmacists/Dispensers & 30 & 19 & 382 & 14 \\
8 & a Other paramedical staff & 671 & 445 & No & No \\
10 & Existence of pharmacovigilance center in hospital & No & No & No & No \\
11 & Maintenance of ADR registers & No & & No \\
\hline
\end{tabular}

ather Paramedical staff includes; medical technicians, ward boys, and sweepers

\section{Data collection}

A data collection form was developed which consisted of seven parts: 1) characteristics of the patients, 2) diagnosis, 3) recommended antibiotics, 4) medication errors, 5) causality assessment by Naranjo score, 6) preventability assessment and 7) the effect of ADRs on organ system (if any). The Anatomical Therapeutic Chemical (ATC) classification system [24] was used for the coding of antibiotics. SPSS version 21.0 was used for calculation of reliability coefficients. Internal consistency was measured by Cronbach's alpha, while reproducibility was evaluated by using intra-class correlation for each item in the scales, with acceptable values $\geq 0.6$. Calculation for Cronbach's alpha was set at 0.76 for Schmuck and Thornton scale, 0.74 for ME tracking form, and 0.78 for Naranjo score. A pilot study was undertaken between November and December 2016 for pre-testing the study instrument. Data were collected between 1st January, 2017 and 30th June, 2017 according to the objectives of the study. The investigational team included a medical practitioner, pharmacist and a nurse. A total of 8 investigational teams were made. Two investigational teams were assigned to each hospital; one for internal medicine ward and other for pediatric ward.

The review of medical record was conducted on daily basis until the patient was discharged from the respective ward. This enables the investigators to scrutinize data from pertinent lab reports, physician's progress notes, patient's medication records (dose, dosage form, frequency and duration of prescribed antibiotics), physician's order, multidisciplinary progress notes and discharge summaries. All the sign and symptoms that appeared after the use of antibiotics were also recorded. The team also participated in ward rounds and checked the presence of any alerts for MEs and ADEs. The expert opinions of physicians and clinical pharmacists were also taken in account before reaching the final decision about the occurrence of ADEs. The LOS in hospital was evaluated by measuring the difference between date of admission from the date of discharge [25]. Although it was difficult to evaluate whether the prolonged LOS in hospital was the contributing factor of ADEs or any underlying disease, so the assessment was made by taking into account the clinical judgments, nature and severity of underlying disease and social factors that may contribute in lengthening the patient's stay time in hospital.

Note: In this study ADEs refers to injuries which are either caused by the drug (i.e., ADRs or non-preventable $A D E s$ ) or by the use of the therapeutic agents (i.e., medication errors or preventable ADEs) while ADRs refer to

Table 2 Characteristics of patients $(N=1249)$

\begin{tabular}{|c|c|}
\hline Characteristics & $\mathrm{n}(\%)^{\mathrm{a}}$ \\
\hline \multicolumn{2}{|l|}{ Gender } \\
\hline Male & $716(57.3)$ \\
\hline Female & $533(42.7)$ \\
\hline \multicolumn{2}{|l|}{ Age } \\
\hline Adults (> 18 years) & $865(69.3)$ \\
\hline Children ( $\leq 18$ years) & $384(30.7)$ \\
\hline \multicolumn{2}{|l|}{ Co-morbidities } \\
\hline Diabetes & $526(42.1)$ \\
\hline Asthma & $424(33.9)$ \\
\hline Tuberculosis & $137(11.0)$ \\
\hline Cystic fibrosis & $162(13.0)$ \\
\hline \multicolumn{2}{|l|}{ Reasons of prescribing antibiotics } \\
\hline Acute respiratory tract infections & $362(29.0)$ \\
\hline Urinary tract infections & $462(37.0)$ \\
\hline Soft tissue infections & $287(23.1)$ \\
\hline Skin infections & $138(11.0)$ \\
\hline \multicolumn{2}{|c|}{ Number of antibiotics prescribed per prescription } \\
\hline 1 & $229(18.3)$ \\
\hline 2 & $603(48.3)$ \\
\hline 3 & $417(33.4)$ \\
\hline \multicolumn{2}{|l|}{ LOS in the hospital } \\
\hline Long ( $\geq 5$ days) & $536(42.9)$ \\
\hline Short (<5 days) & $713(57.1)$ \\
\hline
\end{tabular}

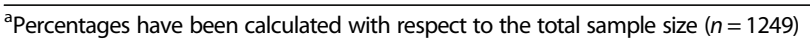


Table 3 Antibiotics prescribed among study population

\begin{tabular}{llll}
\hline Antibiotics Class & ATC code & Number of patients received antibiotics, $N=1249, \mathrm{n}(\%)$ & Number of prescribed antibiotics, $N=2686, \mathrm{n}(\%)$ \\
\hline $\begin{array}{l}\text { P- Lactams } \\
\text { Penicillins }\end{array}$ & J01C & $194(15.5)$ & $261(9.7)$ \\
$\begin{array}{l}\text { Carbapenem } \\
\text { Cephalosporins }\end{array}$ & J01DH & $106(8.5)$ & $234(8.7)$ \\
Non- $\beta$ Lactams & J01D & $223(17.9)$ & $292(10.9)$ \\
Flouroquinolones & J01 M & $291(23.3)$ & \\
Aminoglycosides & J01G & $192(15.4)$ & $316(11.8)$ \\
Tetracyclines & J01AA & $193(15.5)$ & $226(8.4)$ \\
Lincosamide & J01FF & $127(10.2)$ & $221(8.2)$ \\
Macrolides & J01FA & $252(20.2)$ & $209(7.8)$ \\
Glycopeptide & J01XA & $91(7.3)$ & $311(11.6)$ \\
Oxazolidones & J01XX & $102(8.2)$ & $214(7.9)$ \\
Imidazole derivatives & G01AF & $113(9.5)$ & $186(6.9)$ \\
\hline A A Anatomical The & $216(8.0)$ \\
\hline
\end{tabular}

ATC Anatomical Therapeutic Chemical Classification System

the definition given by Edwards and Aronson i.e., unpleasant or harmful reactions that have causal relation with the medicinal product and predicts untoward outcomes from future administration and demands withdrawal from therapy, alteration of dosage regimen and specific treatments [26]. British National Formulary was used for confirming the ADRs [27]. MEs are those that occur during the processing of medication i.e., prescribing, transcribing, dispensing, administering, adherence, or monitoring a drug [28]. MEs were identified through the standard guidelines of Current Medical Diagnosis AND Treatment (CMDT) [29], National Institute of Health and Clinical Excellence (NICE) guidelines [30], British National Formulary (BNF) for children [31] and Infectious Diseases Society of Pakistan (IDSP) guidelines for antibiotic use [32].

\section{Outcome variables}

The outcome variables included causality assessment and preventability assessment. The cases in which ADEs appeared were further analyzed for assessing the preventability by Schumock and Thornton Scale. Medication errors were determined by using medication error tracking form among definitely preventable and probably preventable ADEs. Naranjo scale was used for determining the causal relationship between non-preventable ADEs and antibiotics.

\section{Schumock and Thornton scale}

The Schumock and Thornton criteria [33] was established for assessing the preventability of ADRs. The modified form of this criterion has been used in various studies [34, 35]. It has three sections namely definitely preventable, probably preventable and non-preventable. Section A comprises of five questions while section $B$ has four questions. All the answers are categorized as "Yes" or "No". ADRs were "definitely preventable" if answer was "yes" to one or more questions in section A. If answers were all negative then we proceeded to section B. ADRs were "probably preventable" if answer was "yes" to one or more questions in section B. If answers were all negative then we proceeded to section C. In Section $C$ the ADRs were non-preventable.

\section{Naranjo scale}

The Naranjo Scale was developed by Naranjo and coworkers from the University of Toronto [36] for assessing the likelihood of whether an ADR is due to some particular drug or due to other factors. This validated tool has been used in multiple studies [37, 38]. This scale comprises of 10 questions that are answered "Yes", "No", or "Do not know". Different point values $(-1,0,+$ 1 or +2$)$ are assigned to each answer. Total scores range from -4 to +13 ; the reaction is considered definite if the score is 9 or higher, probable if 5 to 8 , possible if 1 to 4 , and doubtful if 0 or less.

\section{Medication error tracking form}

This tool was prepared for addressing MEs in hospitals for the California Health Care Foundation Data [39]. It consisted of three sections: 1) patient information, 2) medication order information and 3) medication error categorization. The third section comprised of "medication class", "categories" and "possible causes" of MEs. It also classified MEs into five categories: A) prescribing, B) transcribing, C) dispensing, D) administering and E) monitoring. 


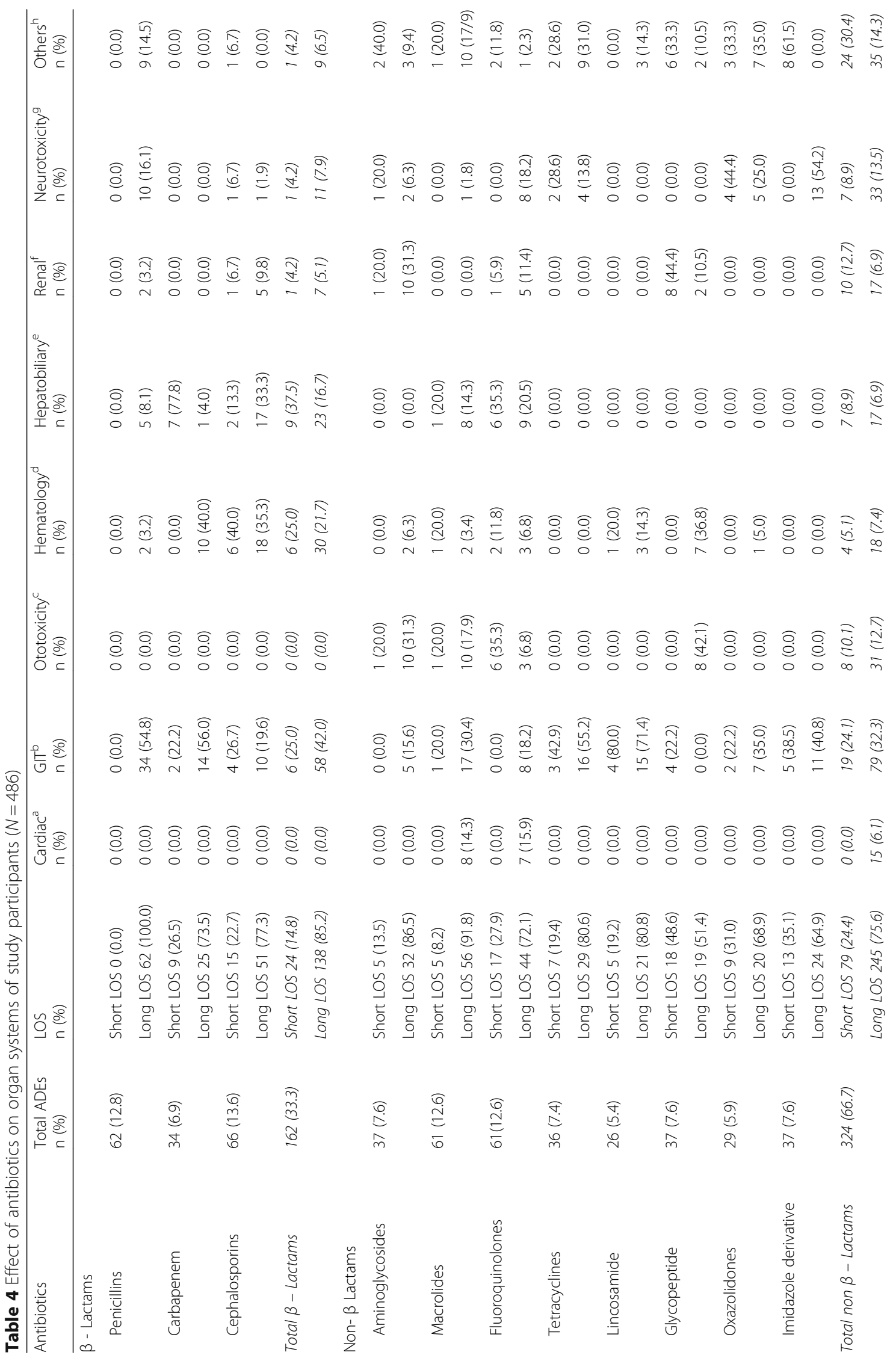




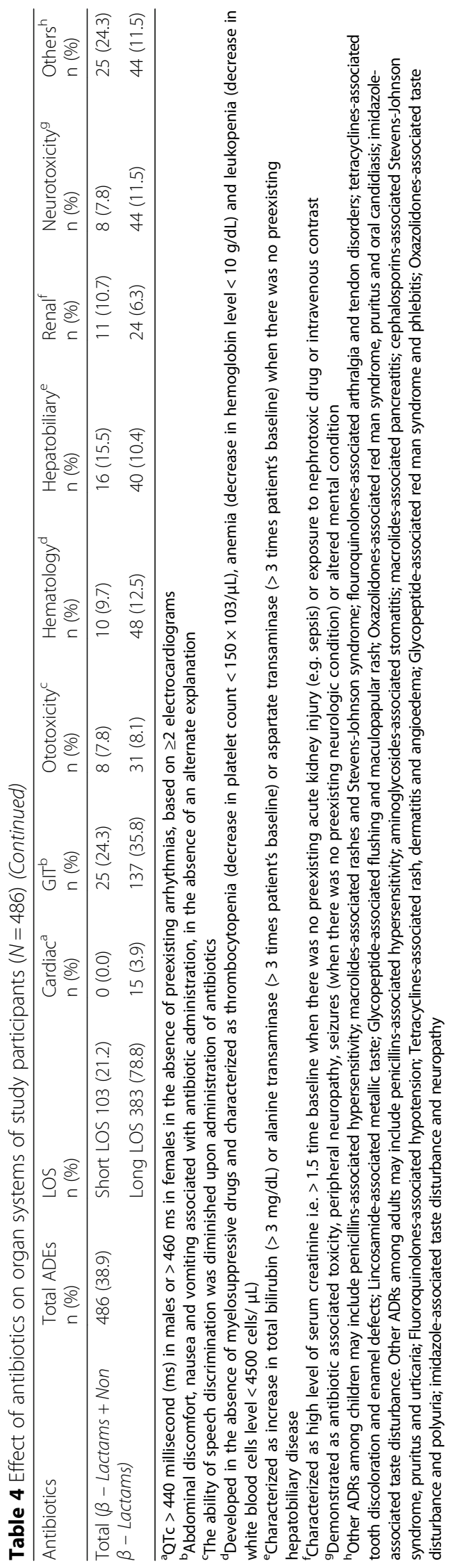




\section{Statistical analysis}

A convenient sampling technique was used to select the study participants. All the patients, admitted in internal medicine and pediatric departments during the 6 months of study period were considered as study population. Among them, patients met the inclusion criteria were taken as a sample size for this study. Statistical Package for Social Sciences (IBM Corp. Released 2012. IBM SPSS Statistics for Windows Version 21.0. Armonk, NY: IBM Corp.) and Microsoft Excel (MS Office 2010) were used for data analysis. Like previously published studies [4042], descriptive statistics such as frequencies and percentages were used to present the data. And logistic regression analysis was performed to figure out the factors associated with ADEs. Results were expressed as Odds Ratio (OR) accompanied by $95 \%$ Confidence Intervals $(95 \% \mathrm{CI})$ and a $p$-value $<0.05$ was used for statistical significance of differences.

\section{Results}

\section{Characteristics of the patients}

According to hospitals records, 14,592 patients were admitted in internal medicine and pediatric departments during the 6 months of study period. A total of 1249 patients (age range 6 to 52 years) met the inclusion criteria of this study. Among them, 57.3\% were male and 69.3\% were aged $>18$ years. $37 \%$ patients $(n=462)$ were prescribed antibiotics for urinary tract infections, $29 \%(n=$ 362) for acute respiratory tract infections, $23 \%(n=287)$ for soft tissue infections and 11\% $(n=137)$ for skin infections. Overall the LOS of $42.9 \%(n=536)$ patients in the hospital was $\geq 5$ days while $57.1 \%(n=713)$ patients stayed for $<5$ days in the healthcare settings (Table 2).

\section{Prescribing pattern of antibiotics}

A total of 2686 antibiotics were prescribed among 1249 patients. Among $\beta$ - Lactams, cephalosporins $(10.9 \%, n$ $=292$ ) while in non $\beta$ - Lactams, fluoroquinolones $(11.8 \%, n=316)$ and macrolides $(11.6 \%, n=311)$ were the most frequently prescribed antibiotics (Table 3).

\section{Organ system affected by ADEs}

The proportion of ADEs was 486 (38.9\%) among the total study participants. Overall, the most affected organ system by both $\beta$-lactams and non $\beta$-lactams antibiotics was GIT (long $\operatorname{LOS}=35.8 \%$, short $\operatorname{LOS}=24.3 \%$ ) as shown in Table 4.

\section{Preventability assessment}

More than half ( $n=383,78.8 \%$ ) of the ADEs were found among patients having long LOS in hospital. Among them, most of the ADEs were preventable i.e., the proportion of definitely preventable ADEs was 171 (44.7\%); whereas, the proportion of probably preventable ADEs was $56(14.6 \%)$ according to modified Schumock and Thornton criteria (Table 5).

Overall most of the definitely preventable $(63.7 \%$, $n=109)$, probably preventable $(69.6 \%, n=39)$ and

Table 5 Preventability assessment $(N=486)$

\begin{tabular}{|c|c|c|c|}
\hline Schumock and Thornton criteria & $\begin{array}{l}\text { Long LOS, } N=383 \text {, } \\
\mathrm{n}(\%)\end{array}$ & $\begin{array}{l}\text { Short LOS, } N=103 \text {, } \\
\mathrm{n}(\%)\end{array}$ & $\begin{array}{l}\text { Total, } N=486, \\
\mathrm{n}(\%)\end{array}$ \\
\hline \multicolumn{4}{|l|}{ Section A: Definitely preventable ADEs } \\
\hline Was there a history of allergy or previous reaction to the drug? & $4(1.0)$ & $5(4.9)$ & $9(1.9)$ \\
\hline Was the drug involved inappropriate for the patient's clinical condition? & $100(26.1)$ & $14(13.6)$ & $114(23.5)$ \\
\hline $\begin{array}{l}\text { Was the dose, route, or frequency of administration inappropriate for } \\
\text { patient's age, weight or disease state? }\end{array}$ & $53(13.8)$ & $11(10.7)$ & $64(13.2)$ \\
\hline Was toxic serum drug concentration or lab monitoring test documented? & $7(1.8)$ & $9(8.7)$ & $16(3.3)$ \\
\hline Was there a known treatment for ADEs? & $7(1.8)$ & $2(1.9)$ & $9(1.9)$ \\
\hline Total & $171(44.7)$ & $41(39.8)$ & $212(43.6)$ \\
\hline \multicolumn{4}{|l|}{ Section B: Probably preventable ADEs } \\
\hline Was therapeutic drug monitoring or other necessary lab test not performed? & $31(8.1)$ & $7(6.8)$ & $38(7.8)$ \\
\hline Was the drug interaction involved in ADEs? & $4(1.0)$ & $2(1.9)$ & $6(1.2)$ \\
\hline Was poor compliance involved in ADE? & $13(3.4)$ & $4(3.9)$ & $17(3.5)$ \\
\hline Were preventative measures not prescribed or administered to the patient? & $8(2.1)$ & $3(2.9)$ & $11(2.3)$ \\
\hline Total & $56(14.6)$ & $16(15.5)$ & $72(14.8)$ \\
\hline Total (preventable ADEs) & $227(59.3)$ & $57(55.3)$ & $284(58.4)$ \\
\hline \multicolumn{4}{|l|}{ Section C: Non-preventable ADEs or ADRs } \\
\hline If all the above criteria not fulfilled. & $156(40.7)$ & $46(44.7)$ & $202(41.6)$ \\
\hline
\end{tabular}




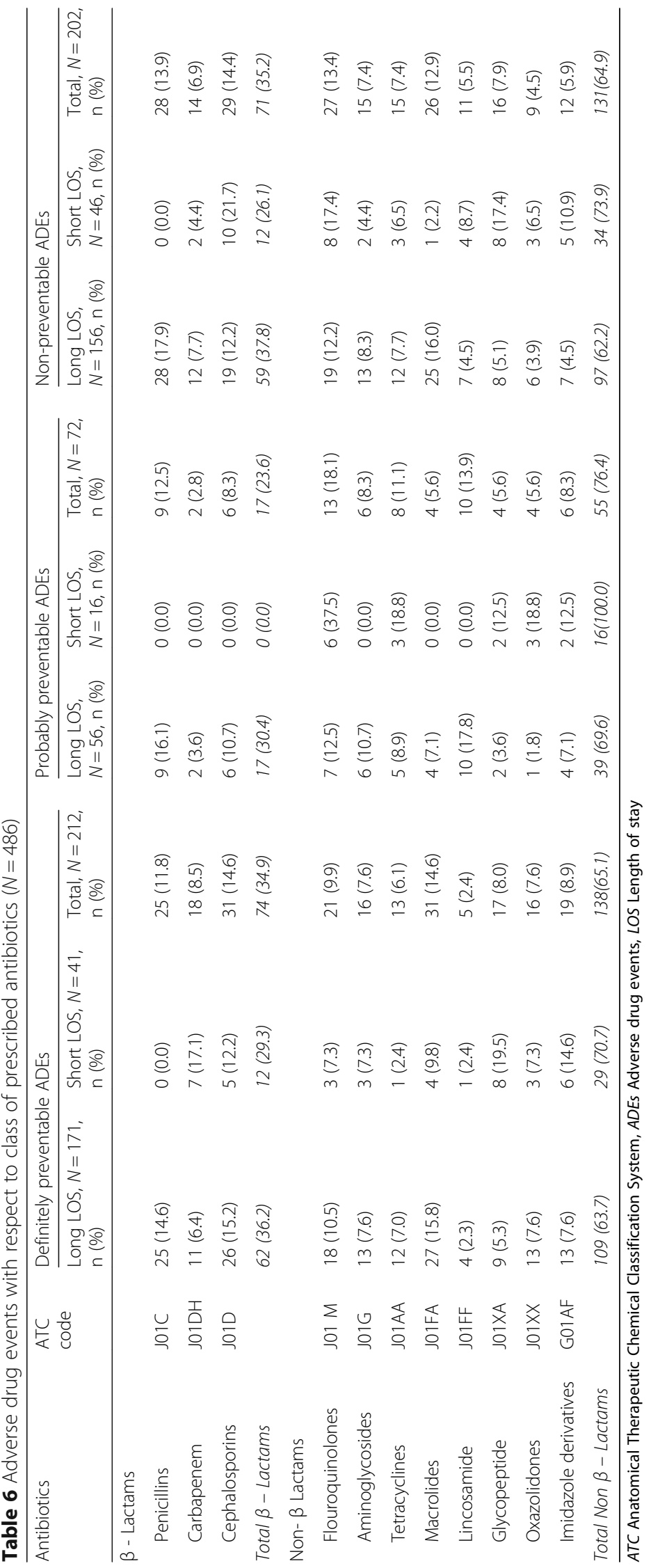


non-preventable ADEs $(62.2 \%, n=92)$ were most commonly caused by non $\beta$-Lactams as compared to $\beta$-Lactams class of antibiotics especially among patients having long LOS in hospital (Table 6).

\section{Medication errors}

Among 284 cases of preventable ADEs, the wrong drug errors $(n=114,40.1 \%)$ and monitoring errors $(n$ $=71,25 \%$ ) were more commonly found among study population. The antibiotics administered through oral route had greater ADEs (proportion of ADEs $=4$ out of 5) as compared to the antibiotics administered through parental route (proportion of ADEs $=1$ out of 5). Physician ordering $(22.2 \%, n=63)$ and patient monitoring $(21.1 \%, n=60)$ were the most common stages of medication errors. These errors were caused due to non-adherence of policies and procedures $(38.4 \%, n=109)$ and lack of information about antibiotics $(32 \%, n=91)$ (Table 7).

\section{Causality assessment}

156 (77.2\%) ADEs were detected among patients having long LOS (> 5 days) and 46 (22.3\%) among patients having short LOS ( $\leq 5$ days). Overall, most of the ADRs were "probable" (long LOS $=35.3 \%$, short LOS $=34.8 \%$ ) and "possible" (long LOS $=33.9 \%$, short $\operatorname{LOS}=30.4 \%$ ) and occurred more frequently due to non $\beta$ lactams as compared to $\beta$ lactams antibiotics (Table 8).

\section{Determinants associated with ADEs among study respondents}

Logistic regression analysis was used to examine the association between ADEs and the independent variables. Results of this analysis revealed that females had 95.3\% less ADEs $(\mathrm{OR}=0.047,95 \% \mathrm{CI}=0.018-0.121, p$-value $=<0.001)$ as compared to males. Among the age groups, patients aged $>18$ years $(\mathrm{OR}=0.041,95 \% \quad \mathrm{CI}=$ $0.013-0.130, p$-value $=<0.001)$ were likely to have less ADEs as compared to patients aged $\leq 18$ years. While examining the association between co-morbidities and

Table 7 Antibiotic associated errors in study population $(N=284)$

\begin{tabular}{|c|c|c|c|}
\hline Variables & $\begin{array}{l}\text { Long length of stay, } N=227 \text {, } \\
\mathrm{n}(\%)\end{array}$ & $\begin{array}{l}\text { Short length of stay, } N=57 \text {, } \\
\mathrm{n}(\%)\end{array}$ & Total, $N=284, \mathrm{n}(\%)$ \\
\hline \multicolumn{4}{|l|}{ Type of medication errors } \\
\hline Wrong drug & $100(44.1)$ & $14(24.6)$ & $114(40.1)$ \\
\hline Wrong dose & $35(15.4)$ & $6(10.5)$ & $41(14.4)$ \\
\hline Wrong route & $2(0.9)$ & $3(5.3)$ & $5(1.8)$ \\
\hline Wrong time & $13(5.7)$ & $2(3.5)$ & $15(5.3)$ \\
\hline Deteriorated drug & $3(1.3)$ & $0(0.0)$ & $3(1.1)$ \\
\hline Omission & $12(5.3)$ & $3(5.3)$ & $15(5.3)$ \\
\hline Wrong dosage form & $3(1.3)$ & $0(0.0)$ & $3(1.1)$ \\
\hline Non-adherence & $13(5.7)$ & $4(7.0)$ & $17(5.9)$ \\
\hline Monitoring error & $46(20.3)$ & $25(43.9)$ & $71(25.0)$ \\
\hline \multicolumn{4}{|l|}{ Stages of errors } \\
\hline Physician ordering & $59(25.9)$ & $4(7.0)$ & $63(22.2)$ \\
\hline Transcribing & $41(18.1)$ & $7(12.3)$ & $48(16.9)$ \\
\hline Dispensing pharmacist & $36(15.9)$ & $14(24.6)$ & $50(17.6)$ \\
\hline Nurse administering & $37(16.3)$ & $9(15.8)$ & $46(16.2)$ \\
\hline Patient monitoring & $37(16.3)$ & $23(40.4)$ & $60(21.1)$ \\
\hline Others $^{\mathrm{a}}$ & $17(7.5)$ & $0(0.0)$ & $17(5.9)$ \\
\hline \multicolumn{4}{|l|}{ Causes of errors } \\
\hline Lack of knowledge about the patients ${ }^{b}$ & $46(20.3)$ & $2(3.5)$ & $48(16.9)$ \\
\hline Lack of information about antibiotics ${ }^{c}$ & $77(33.9)$ & $14(24.6)$ & $91(32.0)$ \\
\hline Non-adherence to policies and procedures ${ }^{d}$ & $73(32.2)$ & $36(63.2)$ & $109(38.4)$ \\
\hline Miscellaneous ${ }^{\mathrm{e}}$ & $31(13.7)$ & $5(8.8)$ & $36(12.7)$ \\
\hline
\end{tabular}

${ }^{a}$ Medication errors due to patient non-adherence

binformation about allergy, lab tests results, concomitant medications and conditions either not available or noted

'Indication for antibiotic use, compatibility, available dosage form, dosing guidelines and route of administration

dUse of abbreviation in medication ordering, incomplete medication order processed, deviation from treatment protocols, delay in dispensing, use of non-standard dosing schedule, and drug preparation errors

elllegible handwriting of physicians, memory lapse, and unavailability of drugs 
Table 8 Causality assessment with respect to antibiotics class $(N=202)$

\begin{tabular}{|c|c|c|c|c|c|c|c|c|c|c|c|}
\hline \multirow[t]{3}{*}{ Antibiotics Class } & \multirow[t]{3}{*}{ ATC code } & \multicolumn{5}{|c|}{ Long length of stay } & \multicolumn{5}{|c|}{ Short length of stay } \\
\hline & & \multicolumn{4}{|c|}{ Naranjo score } & \multirow{2}{*}{$\begin{array}{l}\text { Total } \\
\text { ADRs }\end{array}$} & \multicolumn{4}{|c|}{ Naranjo score } & \multirow{2}{*}{$\begin{array}{l}\text { Total } \\
\text { ADRs }\end{array}$} \\
\hline & & $\begin{array}{l}\text { Definite }^{a} \\
n(\%)\end{array}$ & $\begin{array}{l}\text { Probable }^{\mathrm{b}} \\
\mathrm{n}(\%)\end{array}$ & $\begin{array}{l}\text { Possible } \\
\text { n (\%) }\end{array}$ & $\begin{array}{l}\text { Doubtful }^{d} \\
\mathrm{n}(\%)\end{array}$ & & $\begin{array}{l}\text { Definite } \\
\mathrm{n}(\%)\end{array}$ & $\begin{array}{l}\text { Probable }^{\mathrm{b}} \\
\mathrm{n}(\%)\end{array}$ & $\begin{array}{l}\text { Possible } \\
\text { n (\%) }\end{array}$ & $\begin{array}{l}\text { Doubtful }^{d} \\
\mathrm{n}(\%)\end{array}$ & \\
\hline \multicolumn{12}{|l|}{$\beta$ - Lactams } \\
\hline Penicillins & J01C & $1(3.6)$ & 15 (53.6) & $4(14.3)$ & $8(28.6)$ & 28 & $0(0.0)$ & $0(0.0)$ & $0(0.0)$ & $0(0.0)$ & 0 \\
\hline Carbapenem & $\mathrm{J} 01 \mathrm{DH}$ & $0(0.0)$ & $5(41.7)$ & $3(25.0)$ & $4(33.3)$ & 12 & $1(50.0)$ & $1(50.0)$ & $0(0.0)$ & $0(0.0)$ & 2 \\
\hline Cephalosporins & J01D & $0(0.0)$ & $7(36.8)$ & $9(47.4)$ & $3(15.8)$ & 19 & $3(30.0)$ & $1(10.0)$ & $1(10.0)$ & $5(50.0)$ & 10 \\
\hline Total $\beta$ - Lactams & & $1(1.7)$ & $27(45.8)$ & $16(27.1)$ & 15 (25.4) & 59 & $4(33.3)$ & $2(16.7)$ & $1(8.3)$ & $5(41.7)$ & 12 \\
\hline \multicolumn{12}{|l|}{ Non- $\beta$ Lactams } \\
\hline Flouroquinolones & $J 01 \mathrm{M}$ & $4(21.1)$ & $6(31.6)$ & $7(36.8)$ & $2(10.5)$ & 19 & $0(0.0)$ & $5(62.5)$ & $2(25.0)$ & $1(12.5)$ & 8 \\
\hline Aminoglycosides & J01G & $2(15.4)$ & $4(30.8)$ & $5(38.5)$ & $2(15.4)$ & 13 & $0(0.0)$ & $1(50.0)$ & $0(0.0)$ & $1(50.0)$ & 2 \\
\hline Macrolides & J01FA & $2(7.1)$ & $5(20.0)$ & $12(48.0)$ & $6(24.0)$ & 25 & $0(0.0)$ & $0(0.0)$ & $1(100.0)$ & $0(0.0)$ & 1 \\
\hline Tetracyclines & J01AA & $0(0.0)$ & $3(25.0)$ & $4(33.3)$ & $5(41.7)$ & 12 & $2(66.7)$ & $0(0.0)$ & $1(33.3)$ & $0(0.0)$ & 3 \\
\hline Lincosamide & J01FF & $0(0.0)$ & $2(28.6)$ & $2(28.6)$ & $3(42.9)$ & 7 & $1(25.0)$ & $3(75.0)$ & $0(0.0)$ & $0(0.0)$ & 4 \\
\hline Glycopeptide & J01XA & $2(25.0)$ & $3(37.5)$ & $1(12.5)$ & $2(25.0)$ & 8 & $0(0.0)$ & $2(25.0)$ & $5(62.5)$ & $1(12.5)$ & 8 \\
\hline Oxazolidones & $J 01 X X$ & $0(0.0)$ & $2(33.3)$ & $4(66.7)$ & $0(0.0)$ & 6 & $0(0.0)$ & $1(33.3)$ & $1(33.3)$ & $1(33.3)$ & 3 \\
\hline Imidazole derivatives & G01AF & $1(14.3)$ & $3(42.9)$ & $2(28.6)$ & $1(14.3)$ & 7 & $0(0.0)$ & $2(40.0)$ & $3(60.0)$ & $0(0.0)$ & 5 \\
\hline \multicolumn{2}{|l|}{ Total Non $\beta$ - Lactams } & $11(11.3)$ & $28(28.9)$ & $37(38.1)$ & $21(21.7)$ & 97 & $3(8.8)$ & $14(41.2)$ & $13(38.2)$ & $4(11.8)$ & 34 \\
\hline \multicolumn{2}{|c|}{ Total ( $\beta$ - Lactams + Non $\beta-$ Lactams) } & $12(7.7)$ & $55(35.3)$ & $53(33.9)$ & $36(23.1)$ & 156 & $7(15.2)$ & $16(34.8)$ & $14(30.4)$ & $9(19.6)$ & 46 \\
\hline
\end{tabular}

${ }^{a}$ Definite ( $\geq 9$ score) ADRs are (1) followed a chronological sequence after the administration of drug or in which the drug had achieved a toxic concentration in the tissues or physiological fluid, and (3) could show improvement when the drug was withdrawal but reappeared on exposure

bProbable (5-8 score) ADRs are (1) followed a chronological sequence after the administration of drug, (2) were in accordance to a recognized pattern of reactions, (3) were not confirmed by the exposure to the suspected drug but by the withdrawal of that drug, and (4) could not be described by features of the patient's disease

'Possible (1-4) ADRs are (1) could be described by features of the patient's disease, (2) followed a chronological sequence after the administration of drug, and (3) were in accordance to a recognized pattern of reactions

${ }^{\mathrm{d} D o u b t f u l}(\leq 0)$ are factors other than a drug are associated with the reactions

ADEs, asthmatic patients $(\mathrm{OR}=0.808, \quad 95 \% \mathrm{CI}=$ $0.598-1.093, \quad p$-value $=0.167)$, tuberculosis patients $(\mathrm{OR}=0.304, \quad 95 \% \quad \mathrm{CI}=0.186-0.497, \quad p$-value $=<$ $0.001)$ and cystic fibrosis patients $(\mathrm{OR}=0.527,95 \% \mathrm{CI}=$ $0.334-0.829$, $p$-value $=0.006$ ) were likely to have less ADEs as compared to diabetic patients. According to diagnosis, patients with acute respiratory tract infections had 99.6\% less ADEs $(\mathrm{OR}=0.004,95 \% \mathrm{CI}=0.01-0.019$, $p$-value $=<0.001)$ and patients with soft tissue infections had $95.1 \%$ less ADEs $(\mathrm{OR}=0.49,95 \% \mathrm{CI}=0.018$ 0.133 , $p$-value $=<0.001)$ as compared to the patients having urinary tract infections. Among the number of antibiotics prescribed per prescription, 2 antibiotics prescribed per prescription had 54.5\% less ADEs (OR $=0.455, \quad 95 \% \quad \mathrm{CI}=0.319-0.650, \quad p$-value $=<0.001)$ while 3 antibiotics prescribed per prescription had 1.529 times more ADEs $(\mathrm{OR}=1.529, \quad 95 \% \mathrm{CI}=$ 1.063-2.198, $p$-value $=0.022)$ as compared to those which had 1 antibiotic prescribed per prescription. According to LOS in hospital, patients with long LOS had 14.825 times more ADEs $(\mathrm{OR}=14.825,95 \% \mathrm{CI}=$ 11.198-19.627, $p$-value $=<0.001)$ as compared to patients who had short LOS (Table 9).

\section{Discussion}

The current study set out to determine the causality and preventability of ADEs associated with the use of antibiotics among inpatients having different LOS in hospital. It was revealed that overall $38.9 \%$ of the patients were detected with ADEs upon administering $\beta$-lactams and non $\beta$-lactams antibiotics. ADRs were less commonly observed as compared to preventable ADEs. MEs especially wrong drug selection might be the possible reason for preventable ADEs. The disobedience of international guidelines and non-availability of national formularies are the biggest hurdles in provision of optimal patient care and thus raise the risk of inappropriate prescribing and MEs [43-48]. This finding is in line with a previously published study where inappropriate prescribing trend of antibiotics had been the cause of majority of the non-preventable ADEs [49]. A study conducted in an Indian healthcare setting also predicted that less than half of the total ADEs were non-preventable and caused by $\beta$-lactams. Most of these non-preventable ADEs had a probable or possible causal relationship with the antibiotics [50]. In Pakistan, the high rate of preventable ADEs is the result of several factors which mainly include, (a) 
Table 9 Logistic regression analysis of factors associated with Adverse drug events $(N=1249)$

\begin{tabular}{|c|c|c|c|c|c|}
\hline \multirow[t]{2}{*}{ Characteristics } & \multicolumn{2}{|l|}{ ADES } & \multirow[t]{2}{*}{$O R$} & \multirow[t]{2}{*}{$95 \% \mathrm{Cl}$} & \multirow[t]{2}{*}{$p$-value } \\
\hline & $\begin{array}{l}\text { Yes } \\
\text { n (\%) }\end{array}$ & $\begin{array}{l}\text { No } \\
\text { n (\%) }\end{array}$ & & & \\
\hline \multicolumn{6}{|l|}{ Gender } \\
\hline Male & $293(23.5)$ & $423(33.9)$ & 1.0 & - & - \\
\hline Female & $193(15.5)$ & $340(27.2)$ & 0.047 & $0.018-0.121$ & $<0.001$ \\
\hline \multicolumn{6}{|l|}{ Age } \\
\hline Children ( $\leq 18$ years) & $184(14.7)$ & $200(16.0)$ & 1.0 & - & - \\
\hline Adults (> 18 years) & $302(24.2)$ & $563(45.1)$ & 0.041 & $0.013-0.130$ & $<0.001$ \\
\hline \multicolumn{6}{|l|}{ Co-morbidities } \\
\hline Diabetes & $210(16.8)$ & $316(25.3)$ & 1.0 & - & - \\
\hline Asthma & $169(13.5)$ & $255(20.4)$ & 0.808 & $0.598-1.093$ & 0.167 \\
\hline Tuberculosis & $37(3.0)$ & $100(8.0)$ & 0.304 & $0.186-0.497$ & $<0.001$ \\
\hline Cystic fibrosis & $70(5.6)$ & $92(7.4)$ & 0.527 & $0.334-0.829$ & 0.006 \\
\hline \multicolumn{6}{|l|}{ Reasons of prescribing antibiotics } \\
\hline Urinary tract infections & $198(15.9)$ & $264(21.1)$ & 1.0 & - & - \\
\hline Acute respiratory tract infections & $157(12.6)$ & $205(16.4)$ & 0.004 & $0.001-0.019$ & $<0.001$ \\
\hline Soft tissue infections & $131(10.5)$ & $156(12.5)$ & 0.049 & $0.018-0.133$ & $<0.001$ \\
\hline Skin infections & $0(0.0)$ & $138(11.0)$ & 0.000 & $0.000-0.000$ & 0.994 \\
\hline \multicolumn{6}{|c|}{ Number of antibiotics prescribed per prescription } \\
\hline 1 & $101(8.1)$ & $128(10.2)$ & 1.0 & - & - \\
\hline 2 & $153(12.2)$ & $450(36.0)$ & 0.455 & $0.319-0.650$ & $<0.001$ \\
\hline 3 & $232(18.6)$ & $185(14.8)$ & 1.529 & $1.063-2.198$ & 0.022 \\
\hline \multicolumn{6}{|l|}{ LOS } \\
\hline Short ( $<5$ days) & $103(30.7)$ & $610(48.8)$ & 1.0 & - & - \\
\hline Long ( $\geq 5$ days) & $383(8.2)$ & $153(12.2)$ & 14.825 & $11.198-19.627$ & $<0.001$ \\
\hline
\end{tabular}

ADEs Adverse drug events, OR Odd Ratio, Cl Confidence Interval, LOS Length of stay. The variables with $p$-value $<0.05$ are significantly associated with adverse drug events

non-availability of clinical pharmacist during ward rounds and prescription evaluation, (b) improper monitoring and reporting of ADRs, ADEs and MEs due to unestablished pharmacovigilance centers, (c) high patient load in public hospitals, and (d) low budget allocation for healthcare systems by the government [51-56].

Findings also suggested that ADEs associated with the use of $\beta$-lactams and non $\beta$-lactams antibiotics had mainly affected the GIT, hematologic system and skin. These results are in line with the previously published studies that predict the GIT as the most affected organ system by the antibiotic associated ADEs $[57,58]$. The prime reason of it might be the suppression of normal flora of gut upon oral administration of antibiotics that may lead to the pathogenic and non-pathogenic colonization in GIT [59]. Thus, it is the need of the hour to establish a proper pharmacovigilance surveillance system under Drug Regulatory Authority of Pakistan (DRAP) for the proper monitoring and reporting of ADEs in all the primary, secondary and tertiary care settings. This initiative of provincial and federal government will be fruitful in making statistical analysis of ADEs at national level.

Like the previously published studies [58, 60], most of the non-preventable ADEs or ADRs were "probable" and observed in patients having long LOS in hospital. As the under lying diseases may lead to poly pharmacy, so an ADR cannot be designated to have a definite causal association with the single therapeutic agent [61]. The causality assessment of antibiotics with ADRs is helpful in providing optimal care, establishing safety measures and preventing the risk of reoccurrence and iatrogenic complications [62].

The statistically significant association was established between ADEs and several risk factors by using logistic regression analysis. These factors mainly include age, gender, co-morbidities, number of drugs which were being exposed to the patient and LOS in hospital. It was found that factors like adult age group, female patients, under lying diseases (tuberculosis and acute respiratory infections), prescribing 2 antibiotics per prescription and 
short LOS ( $>5$ days) were significantly less associated with the development of ADEs. Similar association of age and prescribing antibiotics with ADEs was also significantly found in a previously published study [63]. The physiological and pharmacological differences may cause drugs to respond differently among different age groups [64]. Another study revealed significant association of ADEs with the number of drugs exposed but insignificant association was found with the age and gender [65]. As the risk of drug interactions is directly proportional to the number of drugs prescribed per prescription, so it may lead to the development of ADEs [66]. The significant correlation of male gender with the development of ADEs found in the present study is also in line with the previously published literature $[50,67]$. This is in contrast with other studies which showed significant correlation of female gender with the development of ADEs [68, 69]; however, some studies declared no significant association of ADEs with gender $[65,70]$. The prime reason of this divergence is that besides biologic differences several social, behavioral, cultural and physiological dissimilarities may have an impact on factors like gender [71]. It was also found that co-morbidities like diabetes mellitus (DM) had a significant association with ADEs because this metabolic disease may negatively affect the renal function and cause the undesired metabolism of drugs which makes the patients more prone towards the development of ADEs [72]. Long LOS in hospital is also found to be significantly associated with the ADEs which is consistent with the results of previously study wherein most of the preventable ADEs caused an increase in LOS in healthcare settings [73-77]. This is because of the fact that more number of prescribed drugs may increases the risk of drug interactions and MEs and thus leading to increased LOS in the healthcare settings.

This study has some limitations. First, the effects of prescribing multiple drugs at the same time or switching between drugs (bacterial resistance, or changing the medication after a full course treatment) have not been determined. Second, since the data was collected for short period of time and no follow up could be performed after the discharge of patients, so the long term effects of ADEs on organ systems (e.g., liver and kidney) and its risk factors could not be determined. However, future longitudinal studies could address these aspects. Third, the outcomes of treatment interventions like rechallenge and dechallenge were not measured in this study, therefore very few had shown a definite causal association of ADEs with the antibiotics. Last, the Hawthorne effect could have affected the result because physicians, nurses and other paramedical staff were well aware of the study.

\section{Conclusion}

The current study concluded that non $\beta$-lactams were among the most frequently prescribed antibiotics and most of the ADEs caused an increase in LOS in hospital. As per preventability assessment, most of the ADEs were preventable because these were caused due to MEs during the stages of medication processing like physician ordering and patient monitoring. Most of the non-preventable ADEs were having probable causal relationship with the antibiotics and found in patients having prolonged LOS. Gastrointestinal system, hematologic system and skin rashes were commonly found in patients prescribed with both $\beta$-lactams and non $\beta$-lactams. Moreover, the logistic regression showed significant association between ADEs and its risk factors like age, gender, co-morbidities, number of prescribed antibiotics and LOS in hospital. The present findings are beneficial as they give an insight about the current pharmacovigilance system and open the doorsteps for stakeholders in making strategies to overcome these issues.

\section{Abbreviations \\ ADEs: Adverse drug events; ADRs: Adverse drug reactions; DRAP: Drug \\ Regulatory Authority of Pakistan; LOS: Length of stay; MEs: Medication errors;} WHO: World Health Organization

\section{Acknowledgements \\ We would like to express wholehearted thankfulness to the administration of all the selected settings of Lahore, Pakistan. We wish to express gratitude to Dr. Muhammad Atif (Assistant Professor, Islamia University of Bahawalpur) and Dr. Fahad Saleem (Assistant Professor, University of Balochistan), for reviewing and editing the paper and for valuable comments. Also, a note of thanks to all pharmacy students who acted as data collectors.}

\section{Availability of data and materials}

The raw data on which conclusions of this manuscript rely is available on request. Please contact Muhammad Rehan Sarwar at rehansarwaralvi@gmail.com for further details.

\section{Authors' contributions}

MRS conceptualized and designed the study. AS, MS and SI analyzed and interpreted the data. MRS and AS drafted the manuscript. SI, MS and MRS critically revised the manuscript. All authors read and approved final version of the manuscript.

\section{Ethics approval and consent to participate}

The ethical approval was obtained from the Pharmacy Research Ethics Committee (PREC) at Akhtar Saeed College of Pharmaceutical Sciences (Reference: 3-2016/ PREC, December 22, 2016). Before conducting the study, permission was granted from the hospital administrators. The purpose and protocols of this study were thoroughly explained to every participant and their verbal consents were obtained. Written consent was not possible for most of the respondents because either they were illiterate or they had problems in reading and/ or signing the consent document.

\section{Consent for publication}

Not applicable

\section{Competing interests}

The authors declare that they have no competing interests.

\section{Publisher's Note}

Springer Nature remains neutral with regard to jurisdictional claims in published maps and institutional affiliations. 


\section{Author details}

${ }^{1}$ Department of Pharmacy, The Islamia University of Bahawalpur, Bahawalpur, Punjab, Pakistan. ${ }^{2}$ Akhtar Saeed College of Pharmaceutical Sciences, Lahore, Pakistan. ${ }^{3}$ College of Pharmacy, Al Ain University of Science and Technology, Al Ain, Abu Dhabi, UAE.

Received: 16 January 2018 Accepted: 10 June 2018

Published online: 25 June 2018

\section{References}

1. McDonnell PJ, Jacobs MR. Hospital admissions resulting from preventable adverse drug reactions. Ann Pharmacother. 2002;36(9):1331-6.

2. Prevention, N.C.C.f.M.E.R.a., Contemporary view of medication- related harm. A new paradigm. 2015

3. Curtin F, Schulz P. Assessing the benefit: risk ratio of a drug-randomized and naturalistic evidence. Dialogues Clin Neurosci. 2011;13(2):183.

4. Bates DW, et al. Patient risk factors for adverse drug events in hospitalized patients. Arch Intern Med. 1999;159(21):2553-60.

5. Andrews $L B$, et al. An alternative strategy for studying adverse events in medical care. Lancet. 1997;349(9048):309-13.

6. Wester $\mathrm{K}$, et al. Incidence of fatal adverse drug reactions: a population based study. Br J Clin Pharmacol. 2008;65(4):573-9.

7. Stausberg J. International prevalence of adverse drug events in hospitals: an analysis of routine data from England, Germany, and the USA. BMC Health Serv Res. 2014;14(1):125.

8. Lazarou J, Pomeranz BH, Corey PN. Incidence of adverse drug reactions in hospitalized patients: a meta-analysis of prospective studies. Jama. 1998; 279(15):1200-5.

9. Zoppi $\mathrm{M}$, et al. Incidence of lethal adverse drug reactions in the comprehensive hospital drug monitoring, a 20-year survey, 1974-1993, based on the data of Berne/St. Gallen. Eur J Clin Pharmacol. 2000;56(5):427-30.

10. Khan LM, et al. Impact of pharmacovigilance on adverse drug reactions reporting in hospitalized internal medicine patients at Saudi Arabian teaching hospital. Saudi Med J. 2012;33(8):863-8.

11. Macedo AF, et al. Causality assessment of adverse drug reactions: comparison of the results obtained from published decisional algorithms and from the evaluations of an expert panel. Pharmacoepidemiol Drug Saf. 2005;14(12):885-90.

12. Pathak AK, et al. A retrospective analysis of reporting of adverse drug reactions in a tertiary care teaching hospital: one year survey. J Clin Diagn Res. 2016;10(8):FC01.

13. Routledge PA, O'mahony M, Woodhouse K. Adverse drug reactions in elderly patients. Br J Clin Pharmacol. 2004;57(2):121-6.

14. Hecker MT, et al. Unnecessary use of antimicrobials in hospitalized patients: current patterns of misuse with an emphasis on the antianaerobic spectrum of activity. Arch Intern Med. 2003;163(8):972-8.

15. Magill SS, et al. Prevalence of antimicrobial use in US acute care hospitals, May-September 2011. Jama. 2014;312(14):1438-46.

16. Bell $B G$, et al. A systematic review and meta-analysis of the effects of antibiotic consumption on antibiotic resistance. BMC Infect Dis. 2014;14(1):13.

17. Pharmacists, A.S.o.H.-S. Suggested definitions and relationships among medication misadventures, medication errors, adverse drug events, and adverse drug reactions. Am J Health Syst Pharm. 1998;55(2):165-6.

18. Hoonhout LH, et al. Nature, occurrence and consequences of medicationrelated adverse events during hospitalization. Drug Saf. 2010;33(10):853-64.

19. Shehab N, et al. Emergency department visits for antibiotic-associated adverse events. Clin Infect Dis. 2008;47(6):735-43.

20. Martin RM, et al. Age and sex distribution of suspected adverse drug reactions to newly marketed drugs in general practice in England: analysis of 48 cohort studies. Br J Clin Pharmacol. 1998;46(5):505-11.

21. Pretorius RW, et al. Reducing the risk of adverse drug events in older adults. Am Fam Physician. 2013;87(5):331-6.

22. Factbook, C.W. Population of Pakistan 2017; Available from: http://stats.pk/ population-of-pakistan/.

23. Review, W.P. Population of Lahore Census 2017; Available from: http://www. pakinformation.com/population/lahore.html

24. World Health Organization. The anatomical therapeutic chemical classification system with defined daily doses (ATC/DDD). Oslo: WHO; 2006.

25. Government of Penssylvenia. Average Length of Stay in Hospitals. USA. http://www.statistics.health.pa.gov/StatisticalResources/
UnderstandingHealthStats/ToolsoftheTrade/Documents/Average_Length_ of_Stay_in_Hospitals.pdf.

26. Edwards IR, Aronson JK. Adverse drug reactions: definitions, diagnosis, and management. Lancet. 2000;356(9237):1255-9.

27. Committee, J.F. British national formulary (online). London: BMJ Group and Pharmaceutical Press; 2016. URL: www.medicinescomplete.com. Accessed 1 Aug 2015

28. Hepler CD, Segal R. Preventing medication errors and improving drug therapy outcomes: a management systems approach. Boca Raton: CRC Press; 2003.

29. McPhee SJ, Papadakis MA, Tierney LM. Current medical diagnosis \& treatment 2010. New York: McGraw-Hill Medical; 2010.

30. Tan $\mathrm{T}$, et al. Antibiotic prescribing for self limiting respiratory tract infections in primary care: summary of NICE guidance. BMJ. 2008;337:a437

31. Committee, P.F. BNF for children 2014-2015 (BNFC). London: Pharmaceutical Press; 2014

32. Pakistan, T.I.D.S.o. Guidelines for the use of antmicrobials. Pakistan; 2007. http://www.mmidsp.com/wp-content/uploads/2012/06/Guidelines-forAntimicrobial-Use-2.pdf.

33. Schumock GT, Thornton JP. Focusing on the preventability of adverse drug reactions. Hosp Pharm. 1992;27(6):538

34. Kurian J, et al. Adverse drug reactions in hospitalized pediatric patients: a prospective observational study. Indian J Pediatr. 2016;83(5):414-9.

35. Doshi K, Yegnanarayan R, Gokhale N. A retrospective study of drug induced cutaneous adverse reactions (CADR) in patients attending a tertiary care hospital. Curr Drug Saf. 2017;12(1):46-50.

36. Naranjo CA, et al. A method for estimating the probability of adverse drug reactions. Clin Pharmacol Ther. 1981:30(2):239-45.

37. Anderson $\mathrm{M}$, et al. A prospective study of adverse drug reactions to antiepileptic drugs in children. BMJ Open. 2015;5(6):e008298.

38. Trubiano JA, et al. A comparative analysis between antibiotic-and nonantibiotic-associated delayed cutaneous adverse drug reactions. J Allergy Clin Immunol Pract. 2016;4(6):1187-93.

39. Scienes, P. Addressing medication errors in hospitals-ten tools; 2001. p. 47.

40. Padmavathi S, Manimekalai K, Ambujam S. Causality, severity and preventability assessment of adverse cutaneous drug reaction: a prospective observational study in a tertiary care hospital. J Clin Diagn Res. 2013;7(12):2765-7.

41. Leendertse AJ, et al. Frequency of and risk factors for preventable medication-related hospital admissions in the Netherlands. Arch Intern Med. 2008:168(17):1890-6.

42. Pirmohamed $M$, et al. Adverse drug reactions as cause of admission to hospital: prospective analysis of 18820 patients. Bmj. 2004;329(7456):15-9.

43. Khalil S, K.M.T, Khan HS. Irrational use of antibiotics in children. Pak Pediatr J. 2015;39:131-39.

44. Atif $\mathrm{M}$, et al. Assessment of core drug use indicators using WHO/INRUD methodology at primary healthcare centers in Bahawalpur, Pakistan. BMC Health Serv Res. 2016;16(1):684

45. Atif $\mathrm{M}$, et al. Evaluation of prescription errors and prescribing indicators in the private practices in Bahawalpur, Pakistan. J Chin Med Assoc. 2018:81(5):444-9.

46. Atif $M$, et al. WHO/INRUD prescribing indicators and prescribing trends of antibiotics in the Accident and Emergency Department of Bahawal Victoria Hospital, Pakistan. SpringerPlus. 2016;5(1):1928

47. Atif $\mathrm{M}$, et al. Assessment of $\mathrm{WHO} / \mathrm{INRUD}$ core drug use indicators in two tertiary care hospitals of Bahawalpur, Punjab, Pakistan. J Pharm Policy Pract. 2016;9(1):27.

48. Atif $\mathrm{M}$, et al. Drug utilization patterns in the global context: a systematic review. Health Policy Technol. 2017:6:457-70.

49. Trubiano JA, et al. The prevalence and impact of antimicrobial allergies and adverse drug reactions at an Australian tertiary centre. BMC Infect Dis. 2015;15(1):572.

50. Shamna $M$, et al. A prospective study on adverse drug reactions of antibiotics in a tertiary care hospital. Saudi Pharm J. 2014:22(4):303-8.

51. Nazir S. Adverse drug reaction reporting system at different hospitals of Lahore-An evaluation and patient outcome analysis. Value Health. 2014; 17(3):A166.

52. Shamim S, et al. Adverse drug reactions (ADRS) reporting: awareness and reasons of under-reporting among health care professionals, a challenge for pharmacists. SpringerPlus. 2016;5(1):1778.

53. Atif M, Azeem M, Sarwar MR. Potential problems and recommendations regarding substitution of generic antiepileptic drugs: a systematic review of literature. SpringerPlus. 2016;5(1):182. 
54. Atif $\mathrm{M}$, et al. A review indicating the migraine headache as a prevalent neurological disorder: still under-estimated, under-recognized, underdiagnosed and under-treated. J Pharm Pract Community Med. 2017;3(1):3-11.

55. Sarwar MR, et al. Drug utilization patterns among elderly hospitalized patients on poly-pharmacy in Punjab, Pakistan. J Pharm Policy Pract. 2017;10(1):23

56. Sarwar MR, et al. Knowledge of community pharmacists about antibiotics, and their perceptions and practices regarding antimicrobial stewardship: a cross-sectional study in Punjab, Pakistan. Infect Drug Resist. 2018;11:133.

57. de Araújo Lobo MGA, et al. Adverse drug reaction monitoring: support for pharmacovigilance at a tertiary care hospital in Northern Brazil. BMC Pharmacol Toxicol. 2013;14(1):5.

58. Khan, F.A., et al., A prospective study on prevalence of adverse drug reactions due to antibiotics usage in otolaryngology department of a tertiary care hospital in North India. 2013.

59. Hadjibabaie $M$, et al. The adverse drug reaction in the gastrointestinal tract: an overview. Int J Pharmacol. 2005;1(1):1-8.

60. Issac AJ, Yogananda R, Shehin M. Assessment of prescription pattern and monitoring adverse drug reaction of antibiotics in paediatric inpatients. Int J Contemp Pediatr. 2016;3(3):1071-5.

61. Kaur S, et al. Monitoring of incidence, severity, and causality of adverse drug reactions in hospitalized patients with cardiovascular disease. Indian J Pharm 2011:43(1):22-6.

62. Varallo FR, et al. Imputation of adverse drug reactions: causality assessment in hospitals. PLoS One. 2017;12(2):e0171470.

63. Silva DC, et al. Adverse drug events in a paediatric intensive care unit: a prospective cohort. BMJ Open. 2013;3(2):e001868.

64. Kearns $\mathrm{GL}$, et al. Developmental pharmacology_drug disposition, action, and therapy in infants and children. N Engl J Med. 2003;349(12):1157-67.

65. Ji H-h, et al. Adverse drug events in Chinese pediatric inpatients and associated risk factors: a retrospective review using the global trigger tool. Sci Rep. 2018;8(1):2573.

66. Fushiki Y, Kinoshita K, Tokuda Y. Polypharmacy and adverse drug events leading to acute care hospitalization in Japanese elderly. J Gen Fam Med. 2014;15(2):110-6.

67. Jose J, Rao PG, Jimmy B. Adverse drug reactions to fluoroquinolone antibiotics-analysis of reports received in a tertiary care hospital. Int J Risk Saf Med. 2008;20(3):169-80

68. Hussain MM, et al. Incidence of adverse drug reactions in a tertiary care hospital: a systematic review and meta-analysis of prospective studies. Pharm Lett. 2010;2(3):358-68.

69. Stavreva $\mathrm{G}$, et al. Detection of adverse drug reactions to antimicrobial drugs in hospitalized patients. Trakia J Sci. 2008;6(1):7-9.

70. Macy $E, H o ~ N J$. Adverse reactions associated with therapeutic antibiotic use after penicillin skin testing. Perm J. 2011;15(2):31.

71. Alomar MJ. Factors affecting the development of adverse drug reactions. Saudi Pharm J. 2014;22(2):83-94.

72. Haile DB, Ayen WY, Tiwari P. Prevalence and assessment of factors contributing to adverse drug reactions in wards of a tertiary care hospital, India. Ethiop J Health Sci. 2013;23(1):39-48.

73. Davies EC, et al. Adverse drug reactions in hospital in-patients: a prospective analysis of 3695 patient-episodes. PLoS One. 2009;4(2):e4439.

74. Amelung $\mathrm{S}$, et al. Association of preventable adverse drug events with inpatients' length of stay-a propensity-matched cohort study. Int J Clin Pract. 2017;71(10). https://doi.org/10.1111/ijcp.12990.

75. Dedefo MG, Mitike AH, Angamo MT. Incidence and determinants of medication errors and adverse drug events among hospitalized children in West Ethiopia. BMC Pediatr. 2016;16(1):81.

76. Gallo $\mathrm{M}$, et al. Active surveillance of adverse drug reactions in children in five Italian paediatric wards. Open J Pediatr. 2012;2(02):111.

77. Montané E, Arellano AL, Sanz Y, Roca J, Farré M. Drug-related deaths in hospital inpatients: a retrospective cohort study. $\mathrm{Br} J$ Clin Pharmacol. 2018:84(3):542-52.

\section{Ready to submit your research? Choose BMC and benefit from:}

- fast, convenient online submission

- thorough peer review by experienced researchers in your field

- rapid publication on acceptance

- support for research data, including large and complex data types

- gold Open Access which fosters wider collaboration and increased citations

- maximum visibility for your research: over $100 \mathrm{M}$ website views per year

At BMC, research is always in progress.

Learn more biomedcentral.com/submissions 